\title{
A Simplified Parametric Study on Occupant Comfort Conditions in Base Isolated Buildings under Wind Loading
}

\author{
F. Ubertini, ${ }^{1}$ F. Comodini, ${ }^{2}$ A. Fulco, ${ }^{1}$ and M. Mezzi ${ }^{1}$ \\ ${ }^{1}$ Department of Civil and Environmental Engineering, University of Perugia, Via G. Duranti 93, 06125 Perugia, Italy \\ ${ }^{2}$ Faculty of Engineering, University eCampus, Via Isimbardi 10, Novedrate, 22060 Como, Italy \\ Correspondence should be addressed to F. Comodini; fabrizio.comodini@uniecampus.it
}

Received 18 October 2016; Accepted 12 January 2017; Published 19 February 2017

Academic Editor: Kai Qian

Copyright (C) 2017 F. Ubertini et al. This is an open access article distributed under the Creative Commons Attribution License, which permits unrestricted use, distribution, and reproduction in any medium, provided the original work is properly cited.

\begin{abstract}
Vibrations in buildings can cause occupant discomfort in the form of annoyance, headache, or sickness. While occupant comfort is considered in international standards regarding the design of high rise buildings against wind loading, it is neglected in the design of buildings with seismic protective base isolation systems. Nevertheless, due to their low flexibility, base isolated buildings can be prone to wind-induced vibrations, which makes occupant discomfort a potentially significant serviceability limit state. This paper presents a study on occupant comfort conditions in wind-excited base isolated buildings. A numerical simplified parametric procedure is proposed in order to evaluate the return period of wind events causing human discomfort. A parametric investigation is then presented to evaluate the effects of salient parameters on comfort conditions. The procedure is based on (i) the nonlinear dynamic analysis of the structure modeled as a single-degree-of-freedom oscillator with hysteretic base isolators, (ii) the digital generation of time histories of turbulent wind velocity, and (iii) comfort evaluations based on international standards. Results demonstrate that discomfort conditions can occur a few times in a year, depending upon the wind-exposure of the site, what suggests considering this serviceability limit state in the design of base isolated buildings.
\end{abstract}

\section{Introduction}

Occupant discomfort caused by wind-induced vibrations is a major serviceability limit state in the performance-based design of high rise buildings [1], whereby humans have subjective sensitivity to floor acceleration that, in turn, can cause discomfort in the form of annoyance, headache, or sickness.

While it is almost accepted that discomfort is caused by intense floor acceleration, there is no agreement in the scientific literature and in international standard codes, on how to carry out comfort evaluations, as the problem involves aspects that are difficult to model, including physiological and psychological aspects [2]. In this regard, Kwok et al. [3] reviewed existing studies on human perception and associated tolerance thresholds of vibrations in tall buildings, highlighting the need for the development of internationally accepted practical occupant comfort serviceability criteria, accounting for the subjective nature of the problem. Kwon and Kareem [4] compared major international standards in regard to wind effects on buildings and highlighted that most of the technical standards use comfort criteria based on along-wind acceleration. Lamb et al. [5] investigated motion sickness in tall buildings highlighting the importance of considering differences in individual perceptions when examining the effects of building motion on personal comfort, which could also affect work productivity. The same authors reported that the effects of building motions on individual comfort are difficult to assess, because most of the occupants do not complain when they feel discomfort. Bernardini et al. [6] proposed a probabilistic framework for the performancebased design of tall buildings for occupant comfort, providing a computational tool that allows the designer to meet a certain acceptable probability of exceedance of comfort conditions by a certain number of occupants.

While the importance of occupant comfort is wellunderstood in the design of high rise buildings, specific design criteria are considered to limit discomfort caused by wind-induced vibrations.

The same issue is typically neglected in the design of buildings with base isolation devices, with the exception of 


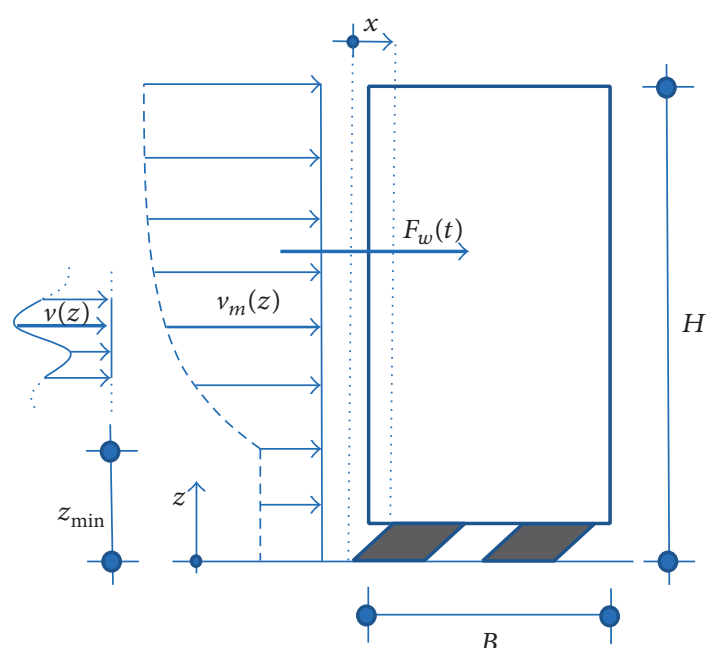

(a)

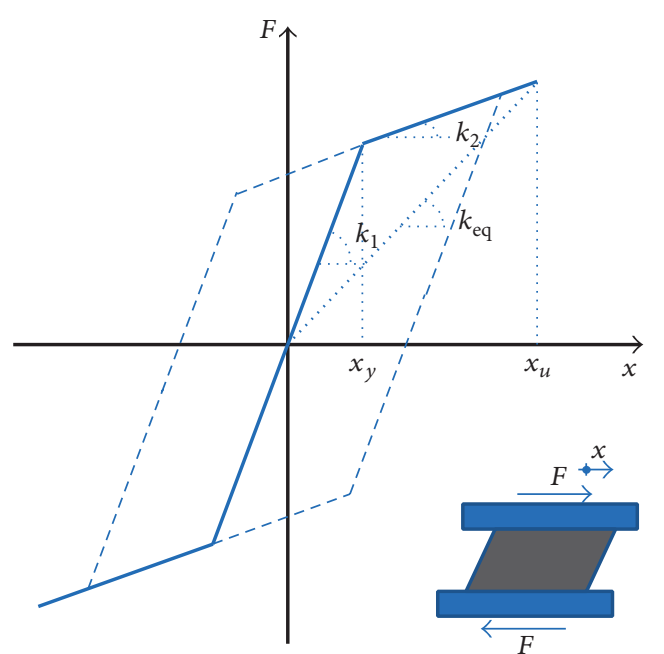

(b)

FIGURE 1: Simplified mechanical system for comfort parametric analysis under wind loading: sketch of the wind-excited base isolated building (a) and constitutive behavior of the base isolation devices (b).

some sporadic attempts that were made at the very beginning of the development of the technology [7]. The comfort conditions assume lesser relevance in earthquake resistant systems such as walls structures [8], while assuming increased relevance for irregular structures [9].

This is motivated by the general understanding that vibration effects caused by wind loading in the case of base isolated buildings are negligible. Nevertheless, base isolated buildings [10], even though often low-rise, have low natural frequencies of vibration, thus being potentially wind-sensitive and prone to wind-induced vibrations $[11,12]$. Thus, the lack of international criteria and standards that account for occupant comfort in base isolated buildings under wind loading does not appear to be fully justified at the present state of the knowledge and the investigation of this problem is a worth research effort, as addressed in this study.

The present paper is a contribution towards a more aware understanding of the role that human comfort conditions may play in the performance-based design of base isolated buildings under wind loading. To this aim, a simple general methodology to evaluate the short term return period of wind events determining discomfort in wind-excited base isolated buildings is proposed, at first. This methodology, presented in Section 2, considers a simple single-degree-of-freedom nonlinear hysteretic oscillator representing a base isolated building under turbulent wind loading and is based on comfort analysis carried out according to widely accepted international standards [13-15]. The model is then used for carrying out some parametric investigations in Section 3, highlighting the major design parameters affecting the critical wind velocity above which discomfort is expected to occur. These results demonstrate that discomfort conditions may occur a few times in a year depending on the wind characteristics of the site and on the characteristics of the base isolated structures. Finally, the paper is ended with proper conclusions in Section 4.

\section{Simplified Analytical Model}

In this section we present the simplified parametric numerical model finalized at rapidly evaluating the return period of wind events determining occupants' discomfort in buildings with base isolation devices. The procedure comprises the following steps:

(1) definition of input parameters regarding both the site and the building;

(2) digital generation of a time history of turbulent wind velocity;

(3) nonlinear dynamic analysis by time integration;

(4) evaluation of the response of the structure in terms of horizontal acceleration;

(5) occupants' comfort analysis according to acknowledged international standards;

(6) assessment of the critical gust intensity determining human discomfort in the building;

(7) evaluation of the return period of wind events causing occupant discomfort.

Steps from (2) to (5) are iterated by considering increasing intensities of the wind gust, so as to determine, in step (6), the critical condition determining discomfort and its corresponding return period in step (7).

2.1. Structural Model. Assuming, without any loss of generality, that the base isolated building has an approximately rectangular plan, with one dimension that is much greater than the other, and that the wind blows along the shorter building dimension, $B$, at a first level of approximation the dynamic behavior of the structure can be modeled by a single-degreeof-freedom nonlinear oscillator (Figure 1(a)), whose equation of motion is

$$
m \ddot{x}(t)+c \dot{x}(t)+k_{\mathrm{nl}}(x(t), \dot{x}(t)) x(t)=F_{w}(t),
$$


where $x(t)$ is the lateral displacement, $t$ denoting time, $m$ is the mass per unit length of the building, $c$ is the damping coefficient, and $F_{w}(t)$ is the wind force per unit length. In (1), the nonlinear restoring force of the base isolation devices is written as

$$
F_{\mathrm{nl}}(x(t), \dot{x}(t))=k_{\mathrm{nl}}(x(t), \dot{x}(t)) x(t)
$$

which is formally similar to an elastic restoring force, but with a nonlinear stiffness coefficient $k_{\mathrm{nl}}(x(t), \dot{x}(t))$. This last is computed by modeling the constitutive behavior of the base isolators through an elastic hardening plastic hysteretic model, also called bilinear hysteretic model [18], as illustrated in Figure 1(b), where $x_{y}$ is the yielding displacement, $x_{u}$ is the ultimate displacement, $k_{1}$ is the initial preyielding stiffness, and $k_{2}$ is the postyielding stiffness. These quantities are calculated as

$$
\begin{aligned}
& k_{1}=\alpha_{k} k_{2}, \\
& k_{2}=\frac{k_{\mathrm{eq}} x_{u}}{x_{u}+\left(\alpha_{k}-1\right) x_{y}},
\end{aligned}
$$

where $k_{\text {eq }}$ is the secant stiffness and $\alpha_{k}$ is a characteristic parameter of the isolators that for elastomeric ones assumes the typical value of 4 [19]. The secant stiffness of the isolators is chosen to meet a certain value of the fundamental period, $T_{0}$, of the isolated mode of the equivalent linear system as follows:

$$
k_{\mathrm{eq}}=m \frac{4 \pi^{2}}{T_{0}^{2}} .
$$

However, it should be noted that, in preyield conditions, occurring in the case of low wind intensities, the system behaves as a relatively rigid linear one, with a fundamental period of the isolated mode, $T_{\text {LIN }}$, given by

$$
T_{\mathrm{LIN}}=2 \pi \sqrt{\frac{m}{k_{1}}}<T_{0}
$$

2.2. Wind Loading Force. The wind loading force is expressed as

$$
\begin{aligned}
F_{w}(t) & =\frac{1}{2} \rho C_{p} \int_{0}^{H}\left(v_{m}(z)+v(z, t)\right)^{2} \mathrm{~d} z \\
& \cong \frac{1}{2} \rho C_{p} \int_{0}^{H}\left(v_{m}^{2}(z)+2 v_{m}(z) v(z, t)\right) \mathrm{d} z,
\end{aligned}
$$

where $\rho$ is the air density, $H$ is the total height of the building from the ground, $C_{p}$ is the pressure coefficient of the building, $v_{m}(z)$ is the ten-minute mean wind velocity at a height $z$ from the ground, and $v(z, t)$ is the turbulent wind velocity. Considering that $v(z, t) \ll v_{m}(z)$, the term $v^{2}(z, t)$, in (6), can be neglected with a good approximation. According to Eurocode 1 [16], the ten-minute mean wind velocity is written as a function of the height from the ground through the classic logarithmic profile that models the atmospheric boundary layer as

$$
\begin{aligned}
& v_{m}(z)=v_{b} k_{R} \ln \left(\frac{z}{z_{0}}\right) \quad z \geq z_{\text {min }}, \\
& v_{m}(z)=v_{b} k_{R} \ln \left(\frac{z_{\text {min }}}{z_{0}}\right) \quad z \leq z_{\text {min }},
\end{aligned}
$$

where $v_{b}$ is the basic wind velocity, which depends upon the geographical location of the site and its altitude above the sea level, $k_{R}$ is the terrain factor, $z_{\text {min }}$ is the height below which the logarithmic profile loses its significance and the mean wind velocity is considered as constant, and $z_{0}$ is the roughness length of the site.

These quantities assume the values summarized in Table 1, which are taken from the Italian technical standard according the definitions of terrain categories reported in Eurocode 1 [16]. The basic wind velocity, $v_{b}$, is instead defined as the tenminute mean wind velocity with a return period of 50 years, irrespective of wind direction, at a height of $10 \mathrm{~m}$ above flat open country terrain (terrain category II).

Substituting (7) into (6) and assuming wind turbulence to be perfectly correlated along the height of the building $(v(z, t)=v(H, t))$ yield

$$
\begin{aligned}
& F_{w}(t)=\frac{1}{2} \rho C_{p} v_{b} k_{R}\left[v _ { b } k _ { R } \left(\ln ^{2}\left(\frac{z_{\min }}{z_{0}}\right) z_{\min }\right.\right. \\
& \left.+\int_{z_{\min }}^{H} \ln ^{2}\left(\frac{z}{z_{0}}\right) \mathrm{d} z\right)+2 \ln \left(\frac{z_{\min }}{z_{0}}\right) v(H, t) z_{\min } \\
& +2 v(H, t)\left[H(\ln (H)-1)-z_{\min }\left(\ln \left(z_{\text {min }}\right)-1\right)\right. \\
& \left.\left.-\ln \left(z_{0}\right)\left(H-z_{\min }\right)\right]\right] \quad H \geq z_{\min }, \\
& F_{w}(t)=\frac{1}{2} \rho C_{p} H v_{b} k_{R} \ln \left(\frac{z_{\min }}{z_{0}}\right)\left[v_{b} k_{R} \ln \left(\frac{z_{\min }}{z_{0}}\right)\right. \\
& +2 v(H, t)] \quad H<z_{\min } .
\end{aligned}
$$

Under the classical assumption of modeling wind turbulence as a zero-mean Gaussian stochastic process [20, 21], time realizations of the turbulent wind velocity are digitally generated through the widely adopted formula based on waves superposition [22], as follows:

$$
v(z, t)=\sum_{k=1}^{N_{\omega}} \frac{1}{2} \sqrt{\Delta \omega S_{v}\left(\omega_{k}\right)} \cos \left(\omega_{k} t+\phi_{k}\right),
$$

where $S_{v}\left(\omega_{k}\right)$ is the power spectral density (PSD) of $v(z, t)$, with $\omega_{k}$ being the circular frequency, $N_{\omega}$ is the number of points in which the PSD is discretized in the interval $\omega \epsilon$ $\left[\begin{array}{ll}0 & \omega_{c}\end{array}\right]$, with $\omega_{c}$ being the cutoff frequency, $\Delta \omega=\omega_{c} / N_{\omega}$ is the step increment in frequency, and $\phi_{k}$ are independent random phase angles having uniform distribution in the $\left[\begin{array}{ll}0 & 2 \pi\end{array}\right]$ range. 
TABLE 1: Terrain categories as defined by Eurocode 1 [16] and corresponding roughness length $z_{0}$, terrain factor $k_{R}$, and parameter $z_{\text {min }}$ according to the Italian technical standard [17].

\begin{tabular}{|c|c|c|c|c|}
\hline Terrain category & Description & $z_{0}(\mathrm{~m})$ & $z_{\min }(\mathrm{m})$ & $k_{R}$ \\
\hline $\mathrm{I}$ & Sea or coastal area exposed to the open sea & 0.01 & 2 & 0.17 \\
\hline II & $\begin{array}{c}\text { Lakes or flat and horizontal area with negligible } \\
\text { vegetation and without obstacles }\end{array}$ & 0.05 & 4 & 0.19 \\
\hline III & $\begin{array}{c}\text { Area with low vegetation such as grass and isolated } \\
\text { obstacles (trees, buildings) with separations of at least } \\
20 \text { obstacle heights }\end{array}$ & 0.10 & 5 & 0.20 \\
\hline IV & $\begin{array}{c}\text { Area with regular cover of vegetation or buildings or } \\
\text { with isolated obstacles with separations of maximum } 20 \\
\text { obstacle heights (such as villages, suburban terrain, } \\
\text { permanent forest) }\end{array}$ & 0.30 & 8 & 0.22 \\
\hline $\mathrm{V}$ & $\begin{array}{l}\text { Area in which at least } 15 \% \text { of the surface is covered with } \\
\text { buildings and their average height exceeds } 15 \mathrm{~m}\end{array}$ & 0.70 & 12 & 0.23 \\
\hline
\end{tabular}

According to Eurocode 1 [16], the PSD of the turbulent wind velocity is modeled as

$$
\frac{\left(\omega_{k} / 2 \pi\right) S_{v}\left(\omega_{k}\right)}{\sigma_{v}^{2}}=\frac{6.8 \cdot\left(\omega_{k} / 2 \pi\right)\left(L_{v} / v_{m}\right)}{\left(1+10.2 \cdot\left(\omega_{k} / 2 \pi\right)\left(L_{v} / v_{m}\right)\right)^{5 / 3}},
$$

where $\sigma_{v}$ is the root mean square of $v(z, t)$ modeled as follows:

$$
\sigma_{v}=k_{R} v_{b}
$$

$L_{v}$ is the integral length scale of turbulence assumed to be equal to

$$
L_{v}=300\left(\frac{z}{200}\right)^{\left(0.67+0.05 \ln \left(z_{0}\right)\right)}
$$

2.3. Response Simulation and Comfort Analysis. The response of the nonlinear system modeled by (1) is obtained by direct time integration using a Runge-Kutta algorithm of order 4, after transformation in state-space first order form. The response is evaluated at discrete time steps, using a total number of time steps $N_{t}=N_{\omega}$ and a sampling time $\mathrm{d} t$.

The comfort analysis is carried out by accounting for the provisions of the most widely acknowledged international standards in the field, namely, ISO 6897 [13], UNI 9614 [14], and ISO 2631-2 [15]. In particular, ISO 6897 [13] refers to the interval from 0.063 to $1 \mathrm{~Hz}$, while UNI 9614 [14] and ISO 26312 [15] provide essentially similar provisions, focusing on the interval from 1 to $80 \mathrm{~Hz}$.

According to the aforementioned international standards, the one-third-octave spectral analysis of the acceleration is carried out in the interval from 0.063 to $80 \mathrm{~Hz}$ and the acceleration levels, $L_{i}$, expressed in $\mathrm{dB}$, where $i$ denotes the $i$ th octave band, are computed as

$$
L_{i}=20 \log _{10} \frac{a_{i}}{a_{0}}
$$

where $a_{i}$ is the effective value (root mean square) of the acceleration in the $i$ th octave band and $a_{0}=10^{-6} \mathrm{~m} / \mathrm{s}^{2}$ is the reference effective acceleration.

In order to carry out the comfort evaluation, it has to be considered that the lower thresholds of human perception of building acceleration depend upon the propagation axis of the vibration referred to the posture of the exposed person. In this regard, axes $z$ and $x-y$ defined in UNI 9614 [14] are considered, as shown in Figure 2. The case of an unknown posture, as considered in UNI 9614 [14], is instead neglected because it yields essentially similar results to the case of the propagation along the $x$ - $y$-axes.

Figure 3(a) depicts the acceleration perception curves as reported in ISO 6897 [13] and UNI 9614 [14]. The acceleration perception curves in the interval $1-80 \mathrm{~Hz}$, represented with continuous lines in Figure 3(a), are taken from the latter standard, while the curve referring to the $x$-y-axes in the interval $0.063-1.0 \mathrm{~Hz}$ is taken from ISO 6897 [13]. It should be noticed that, at $1 \mathrm{~Hz}$, the $x-y$ curves of UNI 9614 and ISO 6897 assume the same value. The curve referring to the $z$-axis in the interval $0.063-1.0 \mathrm{~Hz}$ is instead not reported in any of the considered standards and is here assumed by extending the curve of UNI 9614 below $1 \mathrm{~Hz}$ with a constant slope. It is noted that this branch of the curve is parallel to the curve referring to the $x$ - $y$-axes.

The acceleration threshold curves of Figure 3(a) are transformed into equivalent acceleration level curves, depicted in Figure 3(b), by means of (13). The curves in Figure 3(b) are used to weight the one-third-octave spectral analysis acceleration levels in such a way to make all acceleration levels equivalent in terms of perception and therefore of disturbance. To this aim, the generic acceleration level corresponding to the $i$ th octave, $L_{i}$, is corrected as

$$
L_{i, w}=L_{i}-T_{i}+T_{c}
$$

where $T_{i}$ is the frequency-dependent human threshold level at the $i$ th octave (Figure 3(b)), while $T_{c}$ is a constant threshold.

After application of (14), the level of the total frequency weighted acceleration, $L_{w}$, is computed as

$$
L_{w}=10 \log \sum_{i} 10^{L_{i, w} / 10} .
$$

The comfort analysis consists of verifying the following condition:

$$
L_{w} \leq L_{w, \max }
$$



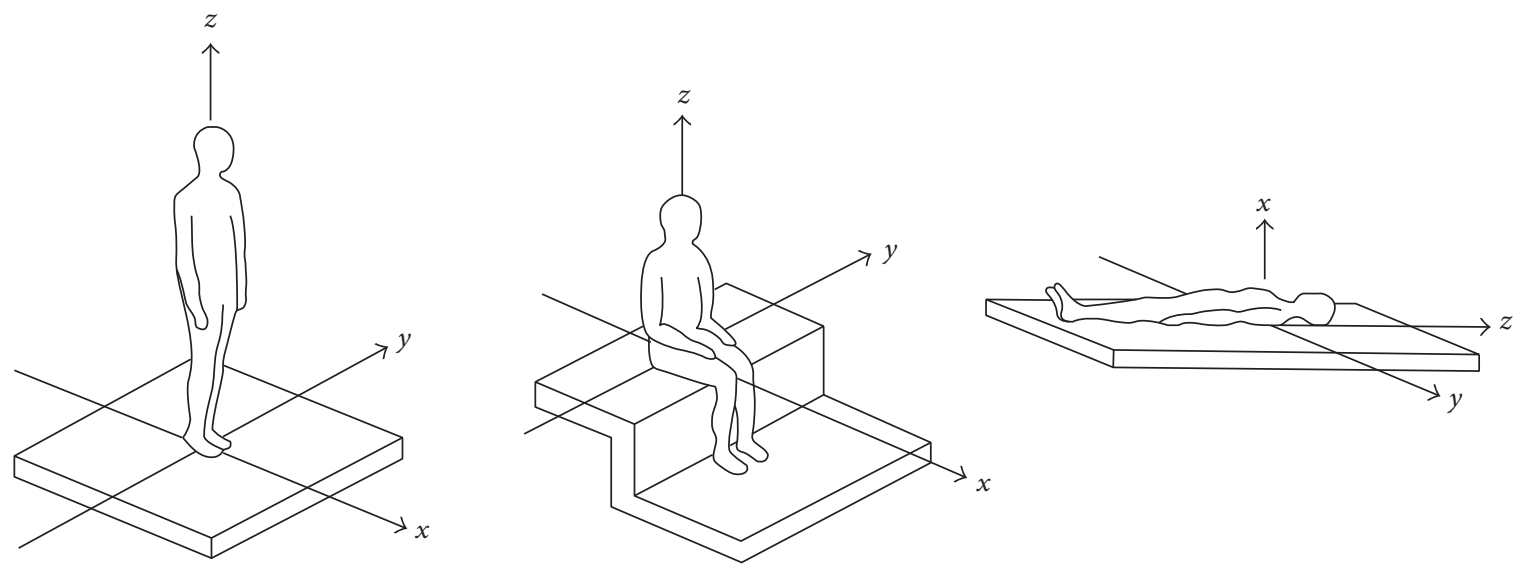

FIGURE 2: Vibration propagation axes as defined in UNI 9614 [14].

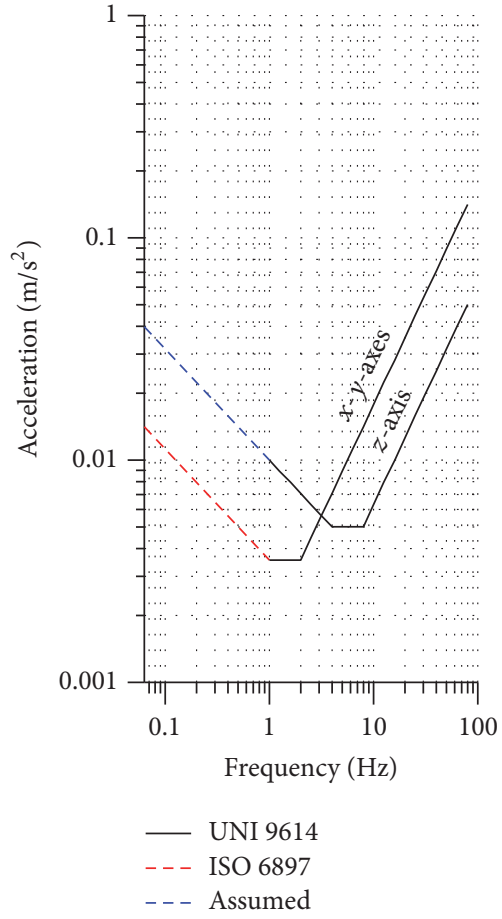

(a)

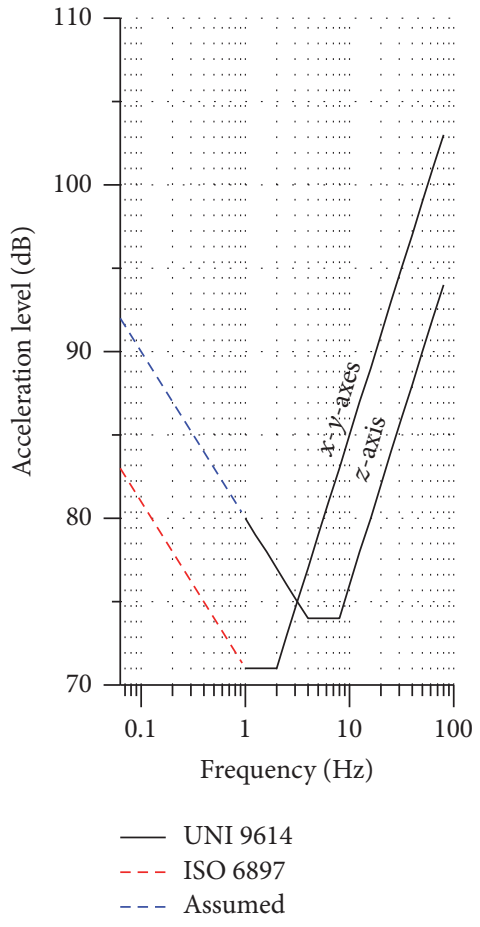

(b)

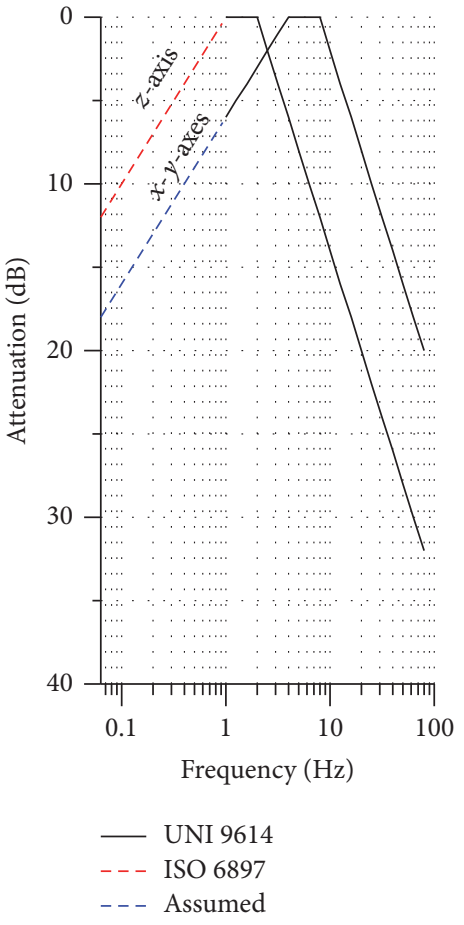

(c)

FIGURE 3: Perception of building motion by humans: adopted acceleration threshold curves (a); corresponding acceleration level curves (b); attenuation curves (c).

where $L_{w, \max }$ represents a critical limit. According to UNI 9614 [14], values of the critical limit are differentiated for socalled "critical areas," residences, offices, and factories, where critical areas are, for instance, operating rooms in hospitals, laboratories, or places where delicate manual works are carried out. The same limit values are also differentiated on the basis of the periods of the day to which the comfort analysis is referred and, in particular, day-time, from 7:00 a.m. to 10:00 p.m., and night-time, from 10:00 p.m. to 7:00 a.m. Values of the critical limits and of the constant threshold, in (14), are summarized in Table 2. Considering that the building acceleration considered in this work are horizontal, propagation along the $z$-axis is only taken into account for residences at night.

2.4. Evaluation of the Return Period of Discomfort. The measure of the gust intensity adopted in this work to evaluate the return period of wind events causing discomfort is the ten-minute mean wind velocity at $10 \mathrm{~m}$ height, denoted as $v_{m, z=10 \mathrm{~m}}$. The critical value of $v_{m, z=10 \mathrm{~m}}$, is the one corresponding to the case where $L_{w}=L_{w, \max }$. The return period, $T_{R}$, of $v_{m, z=10 \mathrm{~m}}$, expressed in years, can be evaluated through the 
TABLE 2: Critical limits for comfort analysis according to UNI 9614 [14].

\begin{tabular}{lccc}
\hline Propagation axis & $T_{c}(\mathrm{~dB})$ & Location and period & $L_{w, \max }(\mathrm{dB})$ \\
\hline$z$ & 74 & Residences (night) & 77 \\
\hline \multirow{4}{*}{$x, y$} & Critical areas & 71 \\
& & Residences (night) & 74 \\
& \multirow{3}{*}{71} & Residences (day) & 77 \\
& & Offices & 83 \\
& & Factories & 89 \\
\hline
\end{tabular}

following equation, derived from the indications contained in Eurocode 1 [16], as a function of the basic wind velocity, $v_{b}$, associated with a return period of 50 years:

$$
\begin{array}{r}
v_{m, z=10 \mathrm{~m}} \\
=k_{R} v_{b} \ln \left(\frac{10 \mathrm{~m}}{z_{0}}\right) \sqrt{\frac{1-0.2 \ln \left(-\ln \left(1-\left(1 / T_{R}\right)\right)\right)}{1-0.2 \ln (-\ln (0.98))}} \\
T_{R}>1 \text { year. }
\end{array}
$$

In the case of a return period shorter than one year, (17) cannot be applied. In this case, $T_{R}$ is approximated by using a spline interpolating curve passing through $\left(T_{R}=0\right.$, $\left.v_{m, z=10 \mathrm{~m}}=0\right)$ and through the curve $v_{m, z=10 \mathrm{~m}}$ versus $T_{R}$, (17), with $T_{R}$ assuming integer values from 1 to 50 . Figure 4 depicts the curves showing $v_{m, z=10 \mathrm{~m}}$ versus $T_{R}$, for $T_{R}$ smaller than 1 year and for different values of $v_{b}$, considering terrain categories from I to $\mathrm{V}$. It is noted that, for fixed values of $v_{m, z=10 \mathrm{~m}}$ and $v_{b}$, the return period monotonically increases with increasing $z_{0}$, that is, with increasing terrain category, due to the effect of $z_{0}$ on the atmospheric boundary layer, (7).

\section{Simulation Results and Discussion}

The simplified model presented in the previous section is adopted to perform some parametric investigations. A specific building example is considered at first and, then, salient parameters of the model are changed in order to evaluate their effects over comfort conditions.

3.1. Analysis for a Building Example. The parameters assumed in the first analysis case are summarized in Table 3. The analysis allows to obtain the curves representing the ratios between the levels of the total frequency weighted acceleration, $L_{w}$, and the critical limits, $L_{w \text {,max }}$, versus the ten-minute mean wind velocity at $10 \mathrm{~m}$ height, $v_{m, z=10 \mathrm{~m}}$. The results of the analysis are presented in Figure 5(a). It is noted that when the wind velocity exceeds a certain critical value, discomfort conditions occur. This critical wind velocity value decreases with decreasing $L_{w \text {, max }}$ (see Table 2), ranging from about $3 \mathrm{~m} / \mathrm{s}$ for critical areas and vibration propagating along $x$ $y$-axes up to about $8 \mathrm{~m} / \mathrm{s}$ for factories. Values of the return period associated with these critical values of ten-minute mean wind velocity at $10 \mathrm{~m}$ height are plotted in Figure 5(b) as functions of the basic wind velocity. It is noted that, for the chosen case study parameters, discomfort conditions can
TABLE 3: Case study and simulation parameters for the first parametric analysis.

\begin{tabular}{lc}
\hline Parameter & Value \\
\hline$T_{0}$ & $2 \mathrm{~s}$ \\
$H$ & $15 \mathrm{~m}$ \\
$B$ & $12 \mathrm{~m}$ \\
$m_{f}$ & $700 \mathrm{~kg} / \mathrm{m}^{2}$ \\
$n_{f}$ & 4 \\
$\xi_{0}$ & 0.01 \\
$x_{u}$ & $0.25 \mathrm{~m}$ \\
$x_{y}$ & $0.04 \mathrm{~m}$ \\
$\alpha_{k}$ & 4 \\
$C_{p}$ & 1.2 \\
$\mathrm{~d} t$ & $0.004 \mathrm{~s}$ \\
$N_{\omega}$ & $2^{16}$ \\
$\omega_{c}$ & $\pi / \mathrm{d} t$ \\
$N_{t}$ & $2^{16}$ \\
\hline Terrain category & $\mathrm{V}$ \\
\hline
\end{tabular}

occur about once every two months in critical areas. Considering that wind storms have typical durations of two-three days, it can be concluded that discomfort conditions may occur a few days in a year.

3.2. Parametric Analysis by Varying Building and Site Characteristics. In order to gain more insight into the investigated problem, it is important to assess how variations in salient model parameters affect the return period of critical wind events. To this aim, the comfort analysis is carried out by varying building and site parameters, one at a time, using the values reported in Table 3 as references.

The parameter that mostly affects the critical wind velocity is the roughness length, which is associated with the terrain category (see Table 1). Figure 6 shows the results obtained by varying such a terrain category, both in terms of critical wind velocity and in terms of return period of discomfort conditions as a function of the basic wind velocity. These results show that the critical wind velocity decreases with increasing roughness length, $z_{0}$, due to an increase in turbulence intensity, according to (11). Because, however, an increase in $z_{0}$ also determines a modification of the mean wind velocity profile, (7), and, consequently, an increase in the return period for a fixed value of the ten-minute mean wind velocity at $10 \mathrm{~m}$ height (Figure 4 ), a lower value of the critical value of such wind velocity does not necessarily entail a lower value of the return period of discomfort, $T_{R}$. This is apparent by looking at the results of Figure 6, where the smallest value of $T_{R}$, equal to 64 days, is obtained for a terrain category III, $z_{0}=0.1 \mathrm{~m}$, and for a basic wind velocity, $v_{b}$, equal to $35 \mathrm{~m} / \mathrm{s}$.

The results of the investigation considering variations in all other building and site parameters are summarized in Figure 7, where the basic wind velocity is assumed to be equal to $27 \mathrm{~m} / \mathrm{s}$ and a terrain category $\mathrm{V}$ is considered. These results confirm that the lowest values of the critical wind velocity are obtained, again, for critical areas and vibrations propagating 


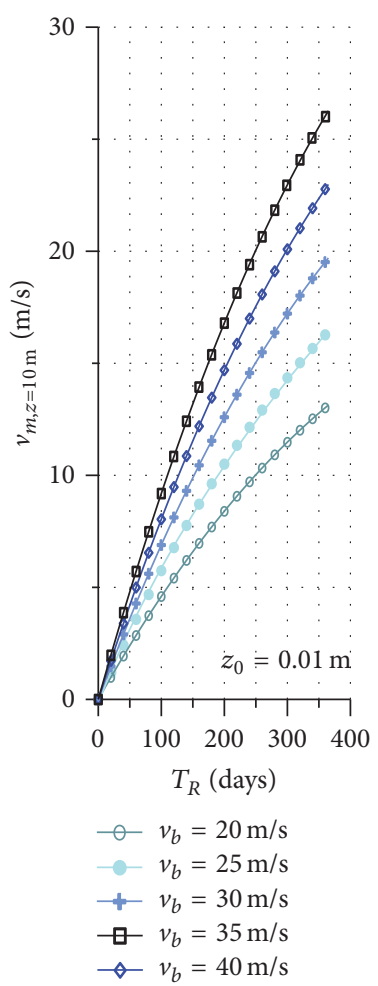

(a)

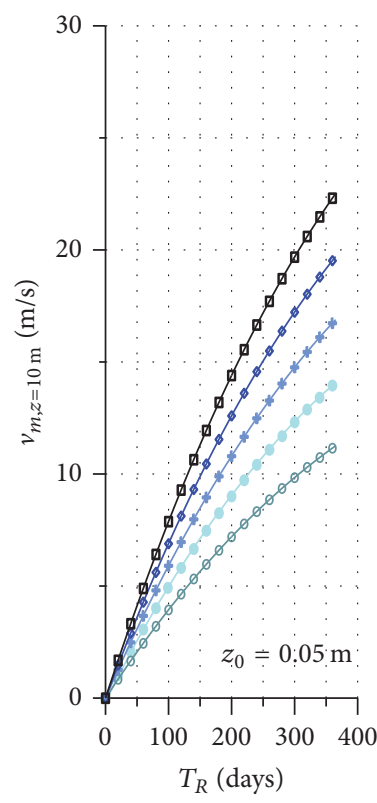

- $v_{b}=20 \mathrm{~m} / \mathrm{s}$

$\rightarrow v_{b}=25 \mathrm{~m} / \mathrm{s}$

$-+v_{b}=30 \mathrm{~m} / \mathrm{s}$

$\rightarrow v_{b}=35 \mathrm{~m} / \mathrm{s}$

$\rightarrow v_{b}=40 \mathrm{~m} / \mathrm{s}$

(b)

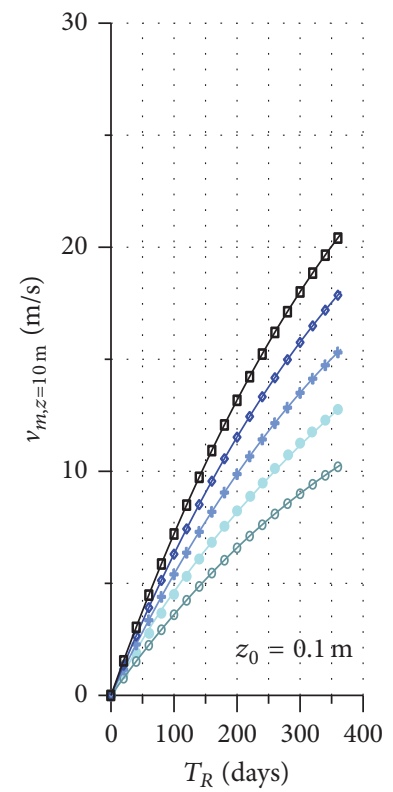

$-v_{b}=20 \mathrm{~m} / \mathrm{s}$

$-v_{b}=25 \mathrm{~m} / \mathrm{s}$

$+v_{b}=30 \mathrm{~m} / \mathrm{s}$

घ- $v_{b}=35 \mathrm{~m} / \mathrm{s}$

$\multimap v_{b}=40 \mathrm{~m} / \mathrm{s}$

(c)

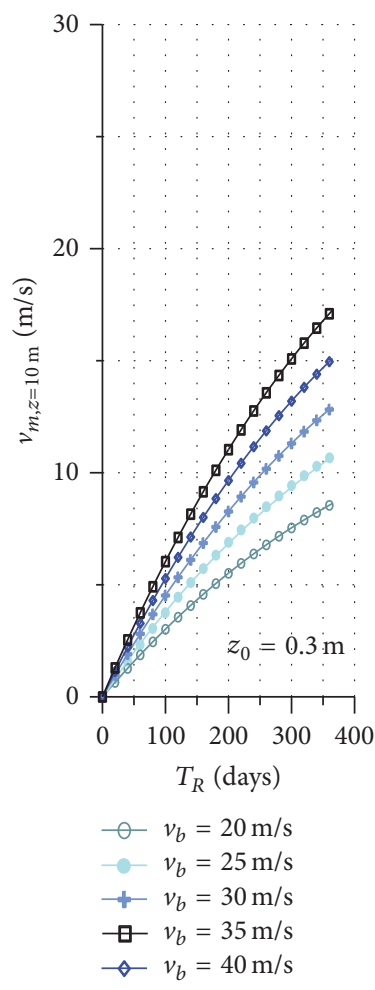

(d)

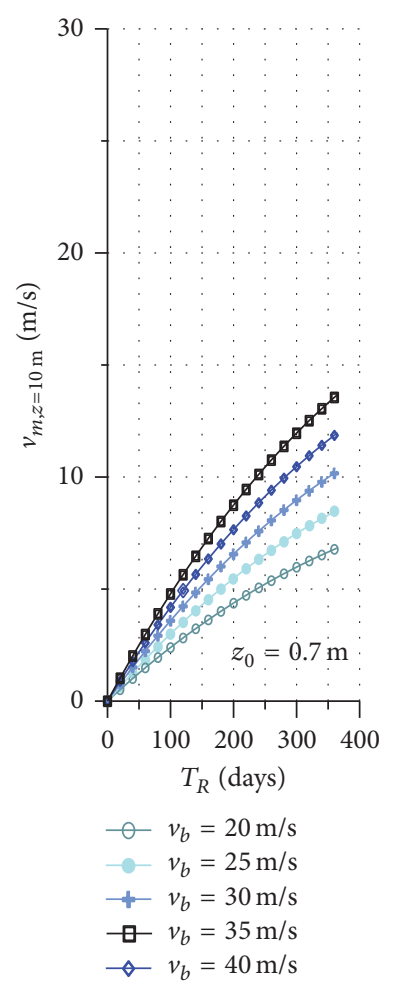

(e)

Figure 4: Values of 10-minute mean wind velocity at $10 \mathrm{~m}$ height as a function of the return period, $T_{R}$, for $T_{R}$ smaller than one year for terrain categories I (a), II (b), III (c), IV (d), and V (e). 


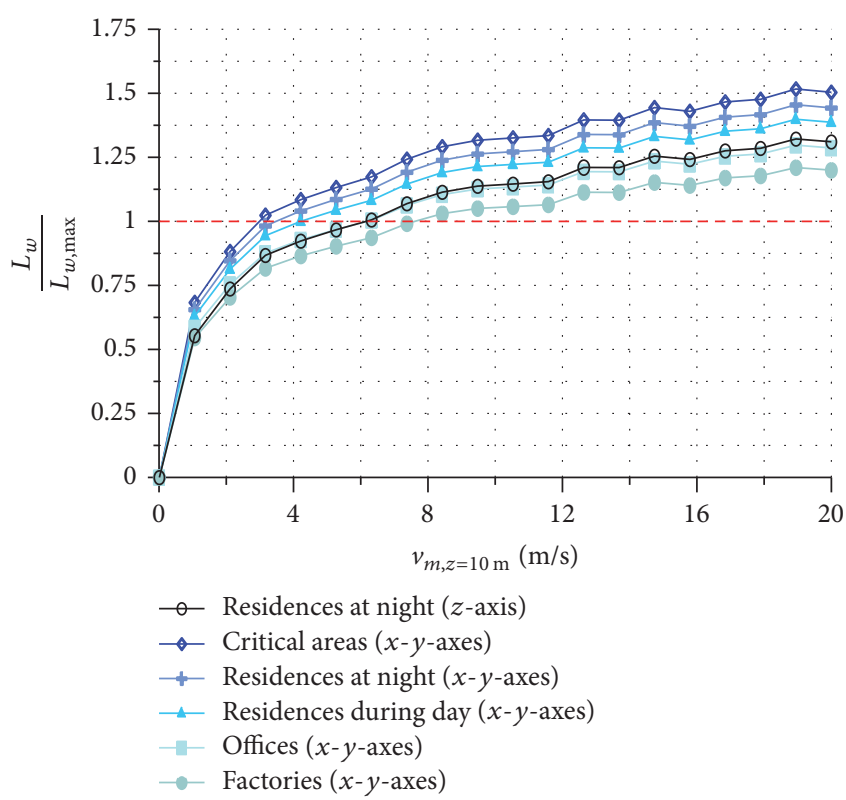

(a)

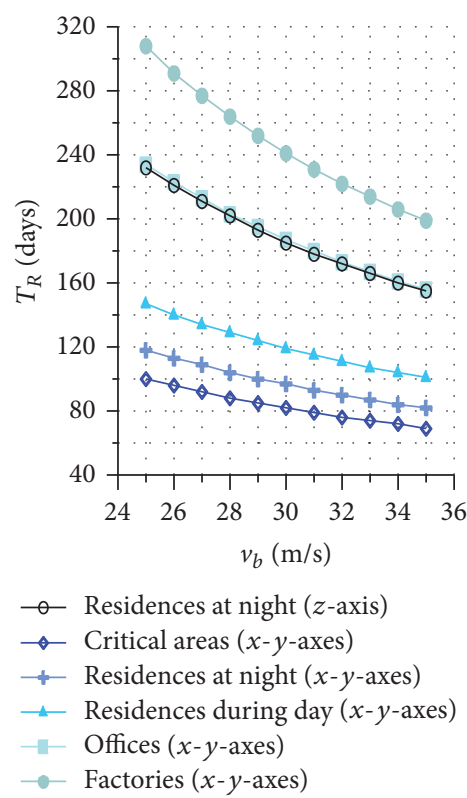

(b)

Figure 5: Results of vibration comfort analysis for the case study of Table 3: ratio between the total frequency weighted acceleration, $L_{w}$, and the critical limit, $L_{w \text {,max }}$, versus the ten-minute mean wind velocity at $10 \mathrm{~m}$ height (a); return period of the critical wind velocity determining discomfort versus the basic wind velocity of the site (b).

along the $x$ - $y$-axes. The same results also show that the return period, $T_{R}$, of discomfort conditions significantly decreases with decreasing building width, $B$, due to a reduction in mass for a constant wind exposed area. For the same reason, $T_{R}$ increases with increasing aerial mass of the floors, $m_{f}$. A slight reduction of $T_{R}$ with increasing $\alpha_{k}$ is observed, which is associated with a reduction of the stiffness of the isolators. On the contrary, $T_{R}$ is marginally affected by the height of the building, $H$, because an increased height, corresponding to an increased wind loading force, is compensated by an increased mass. The effect of an increased damping is, of course, that of reducing the structural vibrations and hence increasing $T_{R}$. As a final remark, some variation of $T_{R}$ with the natural period, $T_{0}$, of the isolated mode of the equivalent linear system is also observed that, however, is not monotonic. In particular, the worst conditions are obtained for $T_{0}$ almost equal to $2 \mathrm{~s}$ and $4 \mathrm{~s}$, while different values of $T_{0}$ result in less critical situations.

Figure 8 shows the results of some time history analyses carried out in order to investigate, in more detail, the role played by the base isolation period, $T_{0}$, of the linearized system on comfort conditions. These results show that the behavior of the system is linear up to relatively large values of the wind velocity, whereby the only case in Figure 8 where the isolators reach the postyield conditions is the one corresponding to $T_{0}=4 \mathrm{~s}$ and $v_{m, z=10 \mathrm{~m}}=15 \mathrm{~m} / \mathrm{s}$. This means that comfort conditions are governed by the fundamental period of the isolated mode, $T_{\mathrm{LIN}}$, in preyield conditions, (5), and by the flexibility of the system. The worst values of $T_{\text {LIN }}$ are those corresponding to natural frequencies comprised in the interval $1-2 \mathrm{~Hz}\left(T_{\mathrm{LIN}}=0.5-1 \mathrm{~s}\right)$ for vibrations along $x-y$-axes (see Figure 3 ). However, a reduction in flexibility is also associated with an increase in vibration amplitudes, which make the variation of $T_{R}$ with $T_{0}$ not monotonic.

\section{Conclusions}

In this paper we have investigated, for the first time in the literature, occupants' comfort conditions in base isolated buildings subjected to turbulent wind loading.

A simple parametric numerical procedure has been developed to estimate the minimum gust intensity that determines occupants' discomfort in the building and the mean recurrence intervals of discomfort conditions. As gust intensity measure, we have considered the ten-minute mean wind velocity at $10 \mathrm{~m}$ height, which is a standard reference for evaluating wind effects on structures and for which historical statistical data are available, as considered in most international codes. The model has been purposely formulated in the simplest way possible, with one single degree of freedom, in such a way to control the effects of the different parameters governing the problem. It considers elastomeric base isolation devices having an elastic hardening plastic constitutive behavior and is based on a classic digital generation formula for wind velocity time histories and on human comfort analysis using international standard provisions based on thirdoctave band spectral analysis of horizontal acceleration and on the application of appropriate filters to account for human perception thresholds.

A parametric study demonstrates that base isolated buildings can undergo discomfort conditions a few times in a year, depending on the site exposure and its geographical location and depending upon the type of building, whereby the worst conditions are observed for critical areas and for residences at 


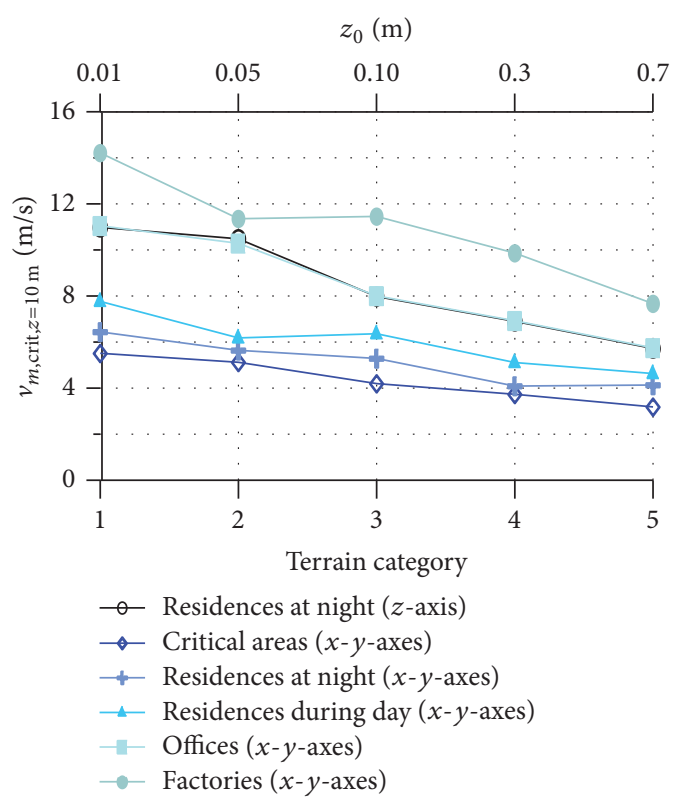

(a)

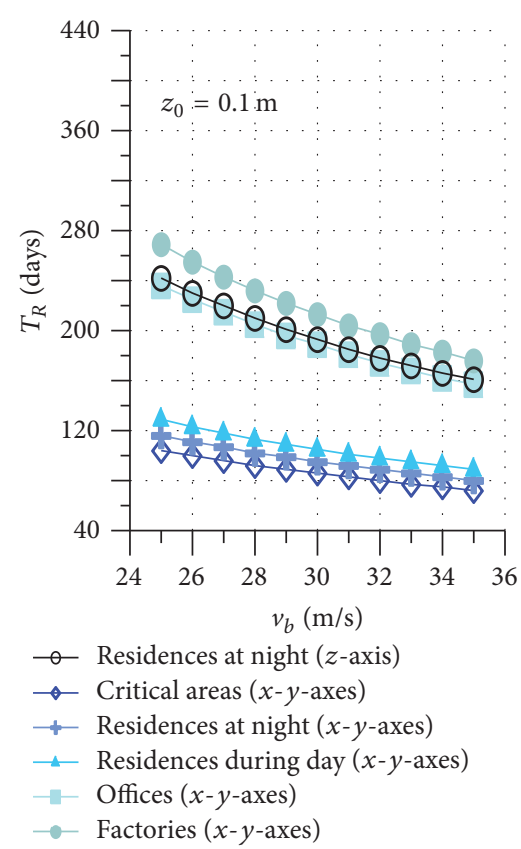

(d)

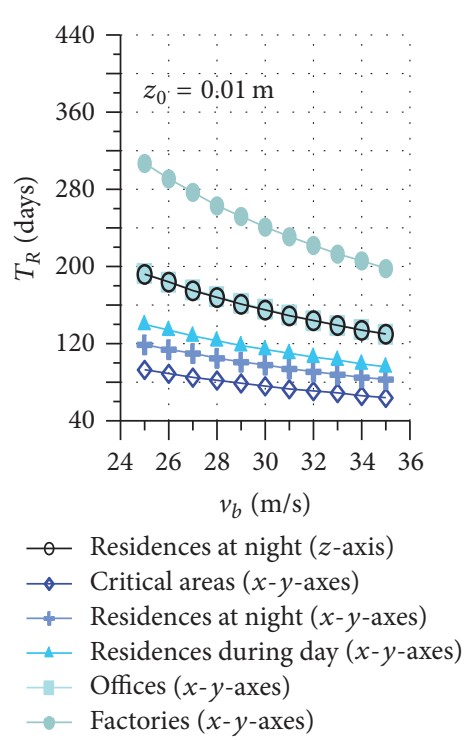

(b)
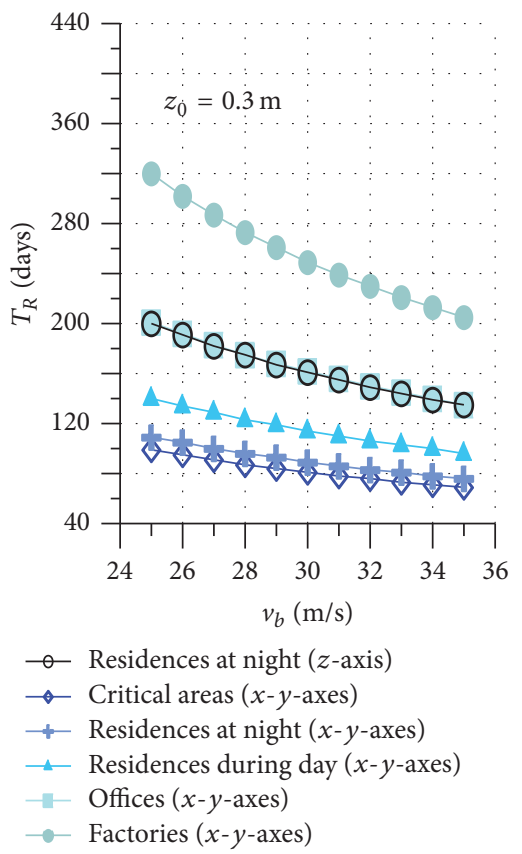

(e)

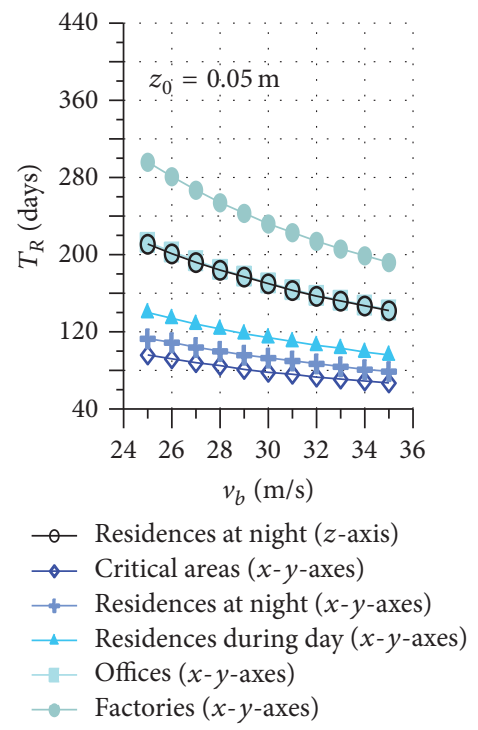

(c)

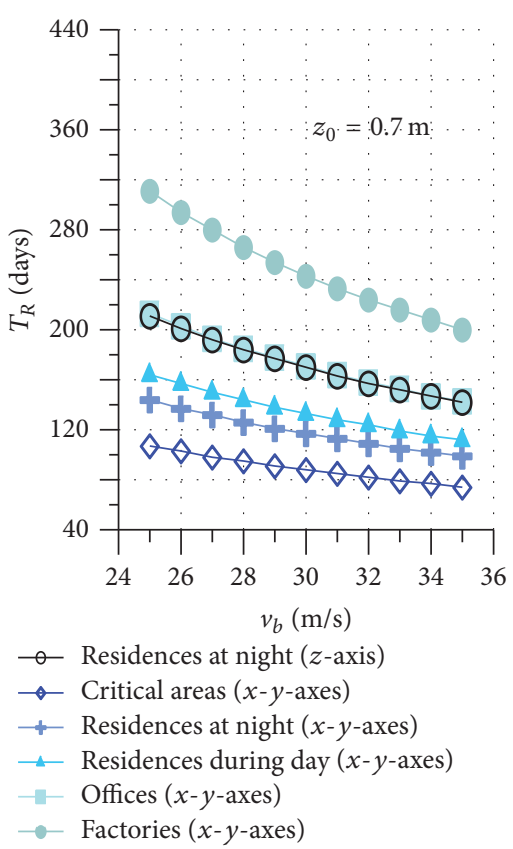

(f)

FIGURE 6: Critical 10-minute mean wind velocity at a height of $10 \mathrm{~m}$ determining discomfort as a function of the terrain category (or roughness length, $z_{0}$ ).

night. The minimum gust intensity determining discomfort is seen to be very sensitive to the terrain category, to the alongwind dimension of the building, and to the aerial mass of the floors, while it is comparatively less sensitive to variations in the base isolation period, the constitutive behavior of the base isolation devices, the height of the building, and the damping ratio of base isolated mode. Furthermore, it has been observed that discomfort occurs at dynamic excitation levels where the behavior of the elastomeric base isolators is still in preyield conditions, so governed by the linear response of the isolators in the range of displacement where their stiffness is maximum.

In conclusions, the analysis presented in this paper demonstrates that human comfort conditions should be considered in the design of base isolation systems, especially for buildings containing critical areas such as hospitals. However, 


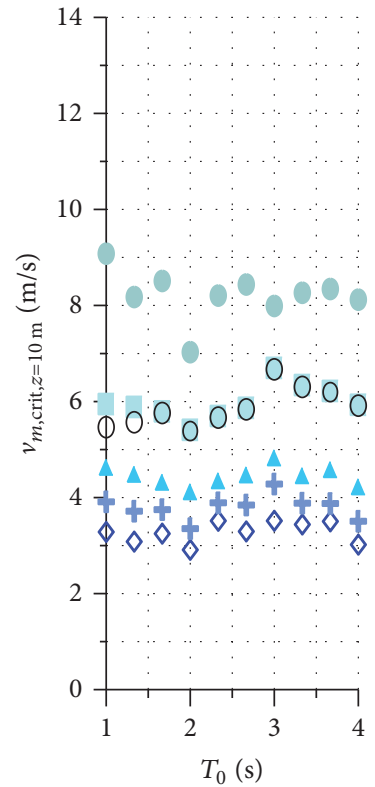

- Residences at night ( $z$-axis)

- Critical areas ( $x$ - $y$-axes)

+ Residences at night ( $x-y$-axes)

$4 \quad$ Residences during day $(x-y$-axes $)$

Offices ( $x$ - $y$-axes)

- Factories ( $x$ - $y$-axes)

(a)

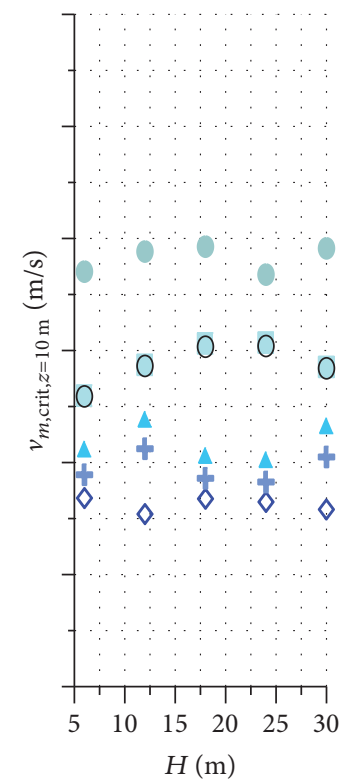

- Residences at night ( $z$-axis)

- Critical areas ( $x$ - $y$-axes)

+ Residences at night ( $x$ - $y$-axes)

Residences during day $(x-y$-axes)

Offices ( $x$ - $y$-axes)

- Factories ( $x$ - $y$-axes)

(b)

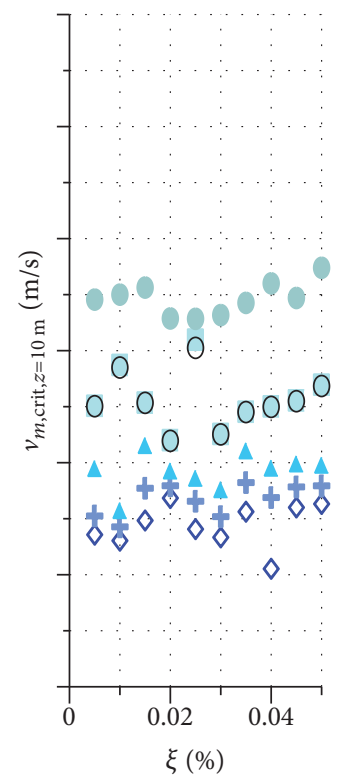

- Residences at night ( $z$-axis)

- Critical areas ( $x-y$-axes)

- Residences at night ( $x$ - $y$-axes)

Residences during day $(x-y$-axes $)$

Offices ( $x$ - $y$-axes)

Factories $(x-y$-axes $)$

(e)

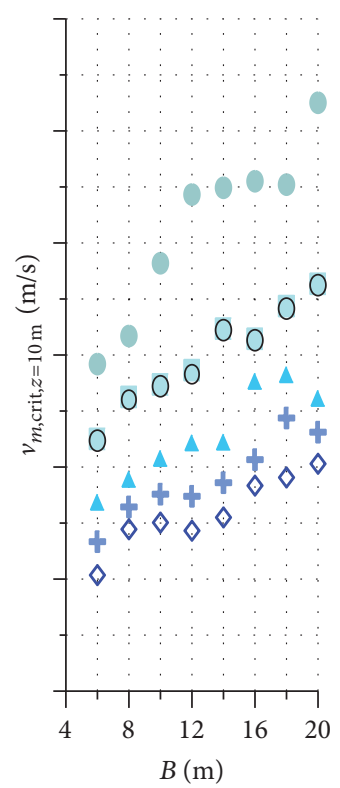

- Residences at night ( $z$-axis)

- Critical areas ( $x$ - $y$-axes)

+ Residences at night ( $x-y$-axes)

$\Delta \quad$ Residences during day $(x-y$-axes)

11 Offices ( $x$ - $y$-axes)

- Factories ( $x$ - $y$-axes)

(c)

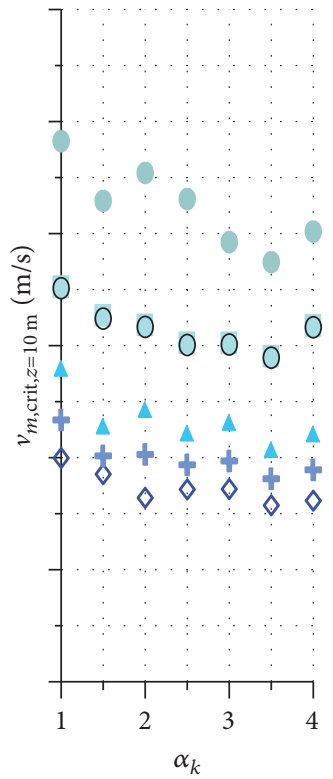

- Residences at night ( $z$-axis)

- Critical areas ( $x-y$-axes)

+ Residences at night ( $x$ - $y$-axes)

$\triangle \quad$ Residences during day $(x-y$-axes)

Offices ( $x$ - $y$-axes)

- Factories $(x-y$-axes $)$

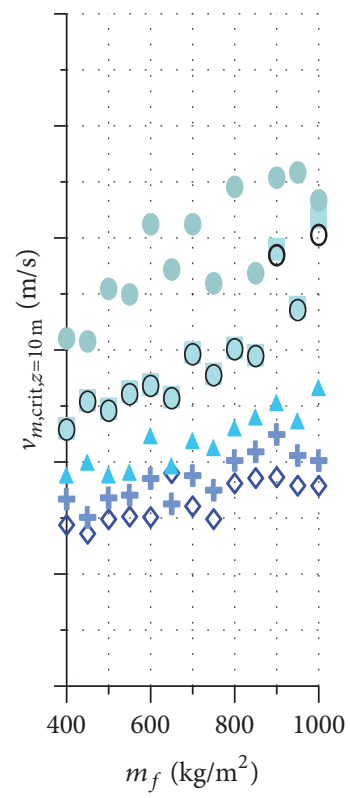

Residences at night ( $z$-axis)

Critical areas ( $x-y$-axes)

- Residences at night $(x-y$-axes $)$

Residences during day $(x-y$-axes)

Offices ( $x$ - $y$-axes)

Factories $(x-y$-axes $)$

(d)

Figure 7: Continued. 


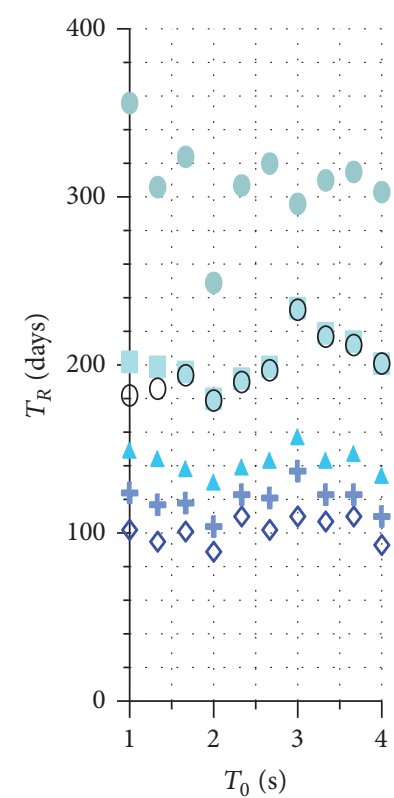

- Residences at night ( $z$-axis)

- Critical areas ( $x$ - $y$-axes)

+ Residences at night ( $x$ - $y$-axes)

$\Delta \quad$ Residences during day $(x-y$-axes $)$

1 Offices $(x-y$-axes $)$

Factories $(x-y$-axes

(g)

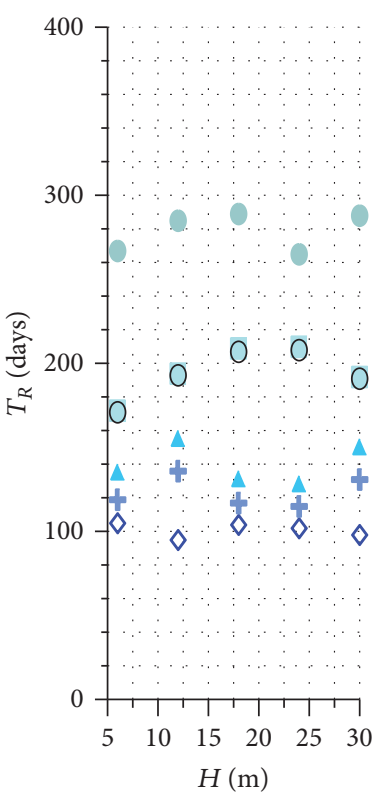

- Residences at night ( $z$-axis)

- Critical areas ( $x$ - $y$-axes)

+ Residences at night ( $x$ - $y$-axes)

$\Delta \quad$ Residences during day $(x$ - $y$-axes $)$

Offices ( $x$ - $y$-axes)

Factories ( $x-y$-axes $)$

(h)

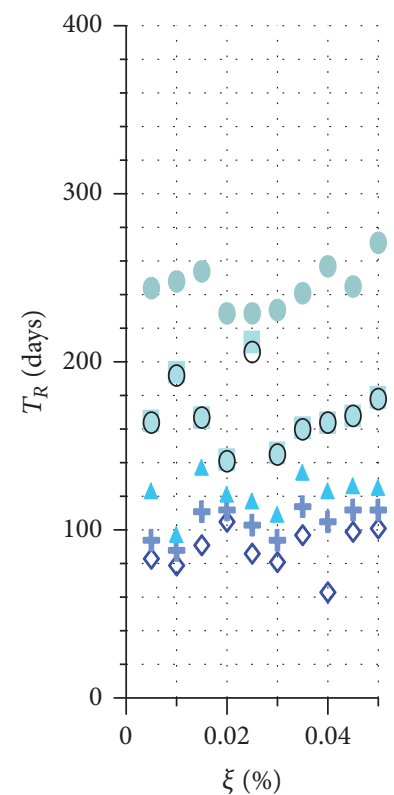

- Residences at night ( $z$-axis)

- Critical areas ( $x$ - $y$-axes)

Residences at night ( $x$ - $y$-axes)

Residences during day $(x$ - $y$-axes $)$

Offices ( $x$ - $y$-axes)

Factories ( $x$ - $y$-axes)

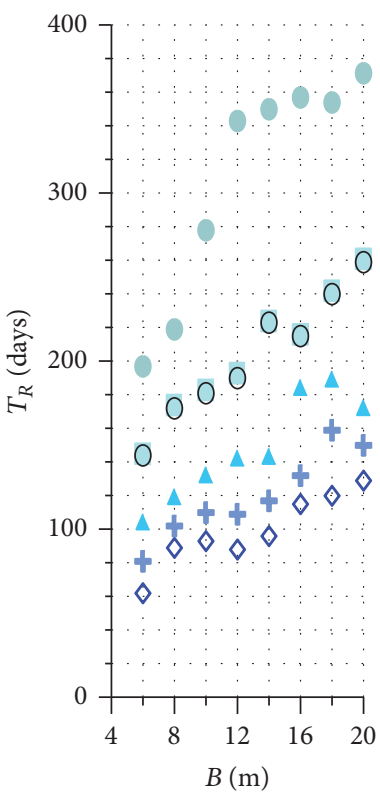

- Residences at night ( $z$-axis)

- Critical areas ( $x$ - $y$-axes)

+ Residences at night ( $x$ - $y$-axes)

$\Delta \quad$ Residences during day $(x-y$-axes)

- Offices ( $x$ - $y$-axes)

- Factories ( $x$ - $y$-axes)

(i)

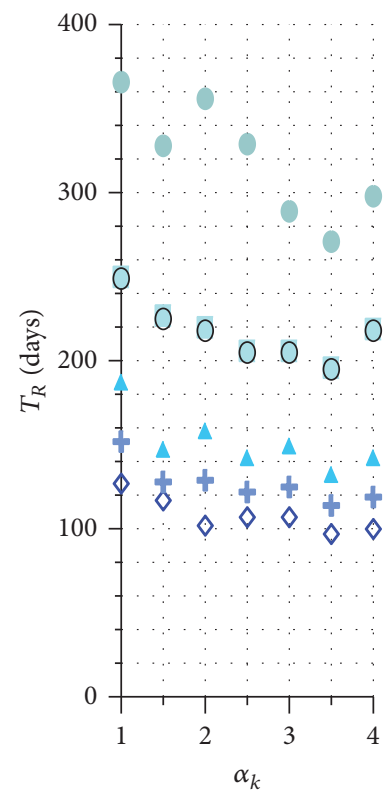

- Residences at night ( $z$-axis)

- Critical areas ( $x$ - $y$-axes)

+ Residences at night ( $x$ - $y$-axes)

$\triangle \quad$ Residences during day $(x$ - $y$-axes)

1- Offices ( $x$ - $y$-axes)

- Factories $(x$ - $y$-axes $)$

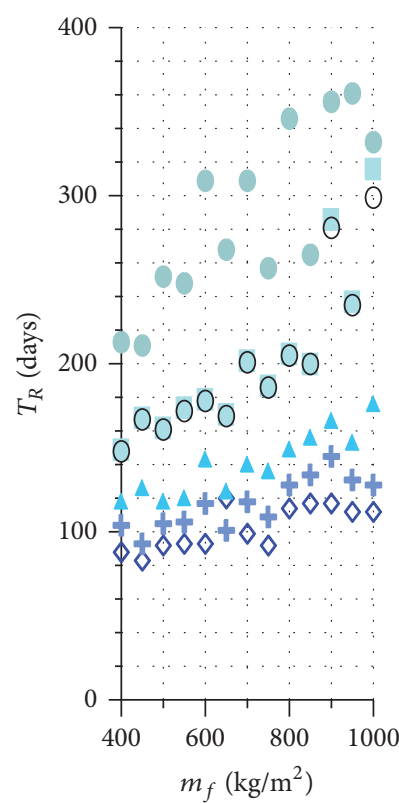

- Residences at night ( $z$-axis)

- Critical areas ( $x$ - $y$-axes)

$+\quad$ Residences at night ( $x$ - $y$-axes)

^ Residences during day $(x$ - $y$-axes $)$

11. Offices ( $x$ - $y$-axes)

- Factories ( $x-y$-axes)

(k)

(l)

Figure 7: Critical 10-minute mean wind velocity at a height of $10 \mathrm{~m}$ determining discomfort and corresponding return period, $T_{R}$, for a basic wind velocity $v_{b}=27 \mathrm{~m} / \mathrm{s}$ and a terrain category $\mathrm{V}$, as a function of the period, $T_{0}$, of the isolated mode of the equivalent linear system (a-g); the height, $H$, of the building $(\mathrm{b}-\mathrm{h})$; the width, $B$, of the building $(\mathrm{c}-\mathrm{i})$; the aerial mass, $m_{f}$, of the floors $(\mathrm{d}-\mathrm{j})$; the damping ratio, $\xi$, of the isolated mode (e-k); the characteristic parameter, $\alpha_{k}$, of the base isolators (f-l). 


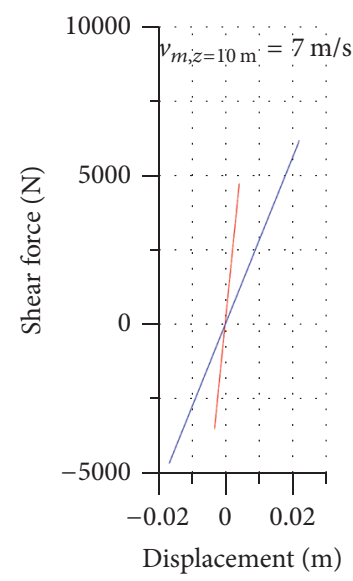

(a)

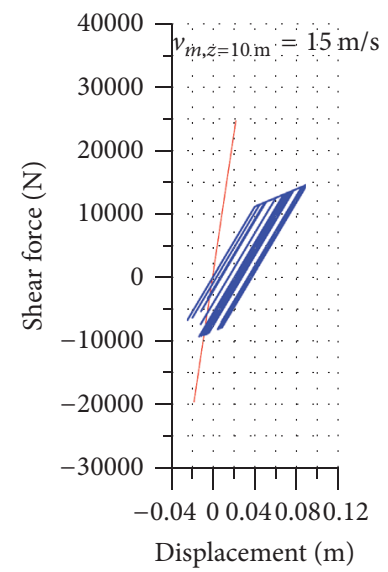

(d)
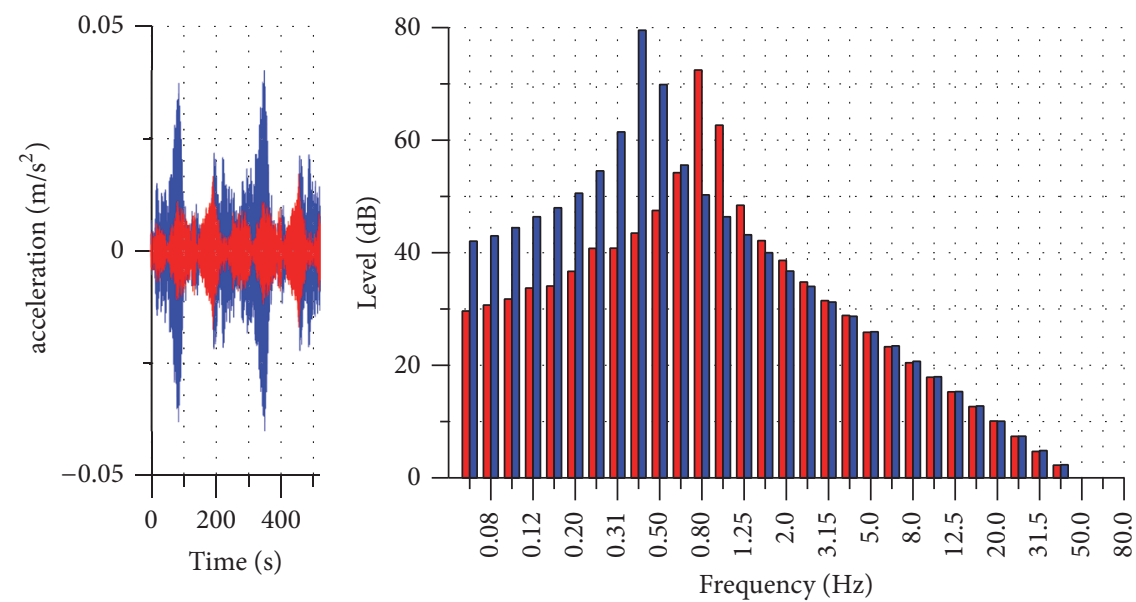

$T_{0}=2 \mathrm{~s}$
$T_{0}=4 \mathrm{~s}$

(b)
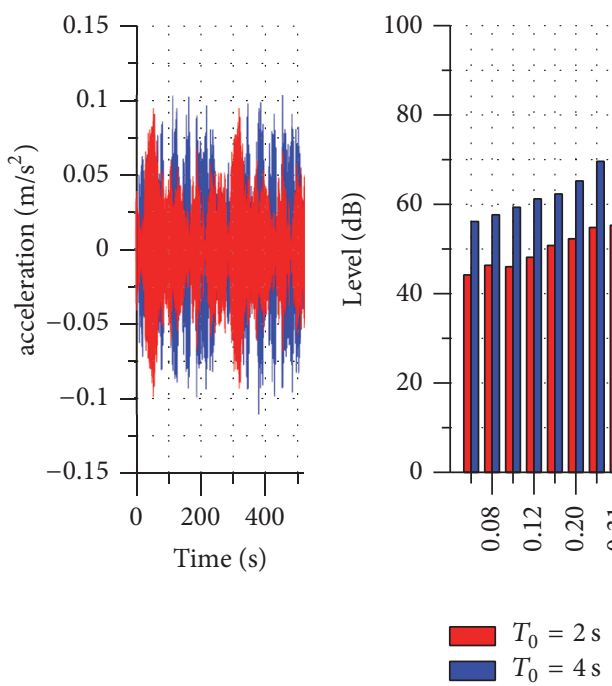

(c)

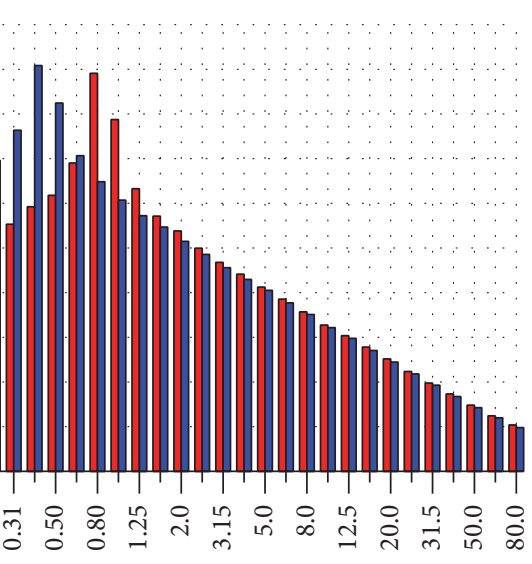

Frequency $(\mathrm{Hz})$

(f)

FIGURE 8: Example of nonlinear dynamic responses with values of the natural period of the equivalent linear system equal to $2 \mathrm{~s}$ and $4 \mathrm{~s}$ : forcedisplacement curves $(a, d)$, time histories of acceleration $(b, e)$, and third-octave analysis levels $(c, f)$ for a 10-minute mean wind velocity at $10 \mathrm{~m}$ height equal to $7 \mathrm{~m} / \mathrm{s}$ and $15 \mathrm{~m} / \mathrm{s}$, respectively.

if evaluated with appropriate methodologies accounting for the frequency content of the motion and for frequencydependent human perception thresholds, as addressed in this study, comfort conditions are not expected to represent a significant design constraint in practice. On the contrary, comfort analysis methods merely based on peak acceleration in the time domain might be too conservative for the considered problem and might significantly underestimate the critical wind velocity causing discomfort.

\section{Competing Interests}

The authors declare that there is no conflict of interests regarding the publication of this paper. The authors confirm that the mentioned received funding in "Acknowledgments" did not lead to any conflict of interests regarding the publication of this manuscript.

\section{Acknowledgments}

This work has been partially supported by ReLUIS project, line 6, "Base Isolation and Dissipation."

\section{References}

[1] G. P. C. Oosterhout, "The wind-induced dynamic response of tall buildings, a comparative study," Journal of Wind Engineering \& Industrial Aerodynamics, vol. 64, pp. 135-144, 1996.

[2] M. D. Burton, K. C. S. Kwok, P. A. Hitchcock, and R. O. Denoon, "Frequency dependence of human response to wind-induced 
building motion," Journal of Structural Engineering (ASCE), vol. 132, no. 2, pp. 296-303, 2006.

[3] K. C. S. Kwok, P. A. Hitchcock, and M. D. Burton, "Perception of vibration and occupant comfort in wind-excited tall buildings," Journal of Wind Engineering and Industrial Aerodynamics, vol. 97, no. 7-8, pp. 368-380, 2009.

[4] D. K. Kwon and A. Kareem, "Comparative study of major international wind codes and standards for wind effects on tall buildings," Engineering Structures, vol. 51, pp. 23-35, 2013.

[5] S. Lamb, K. C. S. Kwok, and D. Walton, "Occupant comfort in wind-excited tall buildings: motion sickness, compensatory behaviours and complaint," Journal of Wind Engineering and Industrial Aerodynamics, vol. 119, pp. 1-12, 2013.

[6] E. Bernardini, S. M. J. Spence, D.-K. Kwon, and A. Kareem, "Performance-based design of high-rise buildings for occupant comfort," Journal of Structural Engineering (United States), vol. 141, no. 10, 2015.

[7] A. Vulcano, "Comparative study of the earthquake and wind dynamic responses of base-isolated buildings," Journal of Wind Engineering and Industrial Aerodynamics, vol. 74-76, pp. 751764, 1998.

[8] F. Comodini, A. Fulco, and M. Mezzi, "Experimental, analytical and numerical analysis of the seismic behavior of Large Lightly R/C Walls cast with Wood Blocks System," Bulletin of Earthquake Engineering, vol. 13, no. 11, pp. 3471-3491, 2015.

[9] M. De Stefano and B. Pintucchi, "A review of research on seismic behaviour of irregular building structures since 2002," Bulletin of Earthquake Engineering, vol. 6, no. 2, pp. 285-308, 2008.

[10] M. Mezzi, F. Comodini, and L. Rossi, "A base isolation option for the full seismic protection of an existing masonry school building," in Proceedings of the 13th International Conference on Civil, Structural and Environmental Engineering Computing, Civil-Comp Proceedings, B.H.V. Topping, Civil-Comp Press, Stirlingshire, UK, 2011.

[11] P. Henderson and M. Novak, "Wind effects on base isolated buildings," Journal of Wind Engineering and Industrial Aerodynamics, vol. 36, part 1, pp. 559-569, 1990.

[12] B. Liang, X. Shishu, and T. Jiaxiang, "Wind effects on habitability of base-isolated buildings," Journal of Wind Engineering and Industrial Aerodynamics, vol. 90, no. 12-15, pp. 1951-1958, 2002.

[13] ISO (International Organization for Standardization), “Guidelines for the evaluation of the response of occupants of fixed structures, especially buildings and off-shore structures, to lowfrequency horizontal motion $(0,063-1 \mathrm{~Hz})$," ISO 6897, Geneva, 1984.

[14] UNI, "Misura delle vibrazioni negli edifici e criteri di valutazione del disturbo," UNI 9614, 1990 (Italian).

[15] ISO 2631-2, Mechanical vibration and shock-evaluation of human exposure to whole-body vibration-part 2: vibration in buildings ( $1 \mathrm{~Hz}$ to $80 \mathrm{~Hz}$ ), 2003.

[16] EN 1991-1-4, Eurocode 1: Actions on Structures-Part 1-4: General Actions-Wind Actions, CEN-European Committee For Standardization, Brussels, Belgium, 2005.

[17] NTC, Norme Tecniche per le Costruzioni, DM 14 gennaio 2008, Gazzetta Ufficiale n. 29 del 4 febbraio 2008, Supplemento Ordinario n. 30. Istituto Poligrafico e Zecca dello Stato, Rome, Italy, 2008.

[18] B. K. Roy and S. Chakraborty, "Robust optimum design of base isolation system in seismic vibration control of structures under random system parameters," Structural Safety, vol. 55, pp. 4959, 2015.
[19] J. M. Kelly and F. Naeim, Design of Seismic Isolated Structures, John Wiley \& Sons, New York, NY, USA, 1999.

[20] L. Carassale and G. Solari, "Monte Carlo simulation of wind velocity fields on complex structures," Journal of Wind Engineering and Industrial Aerodynamics, vol. 94, no. 5, pp. 323-339, 2006.

[21] F. Ubertini and F. Giuliano, "Computer simulation of stochastic wind velocity fields for structural response analysis: comparisons and applications," Advances in Civil Engineering, vol. 2010, Article ID 749578, 20 pages, 2010.

[22] M. Shinozuka and G. Deodatis, "Simulation of stochastic processes and fields," Probabilistic Engineering Mechanics, vol. 12, no. 4, pp. 203-207, 1997. 


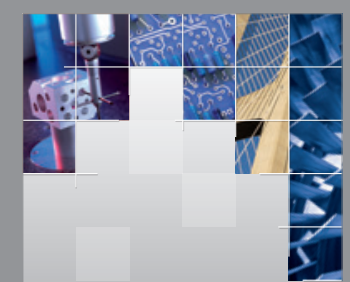

\section{Enfincering}
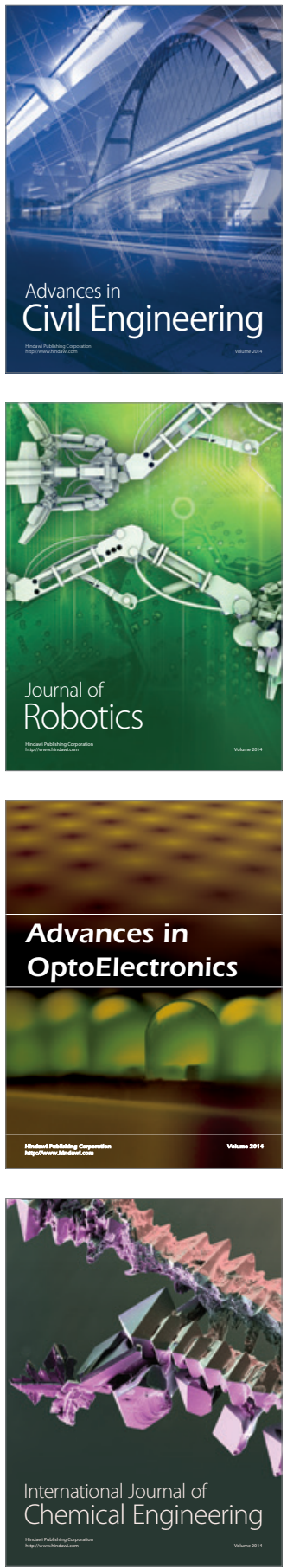

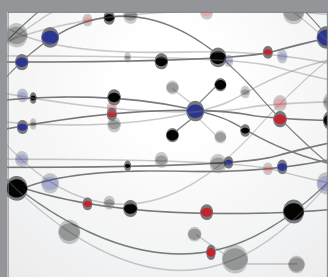

The Scientific World Journal

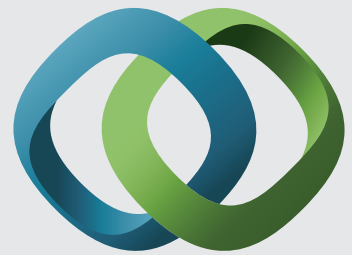

\section{Hindawi}

Submit your manuscripts at

https://www.hindawi.com
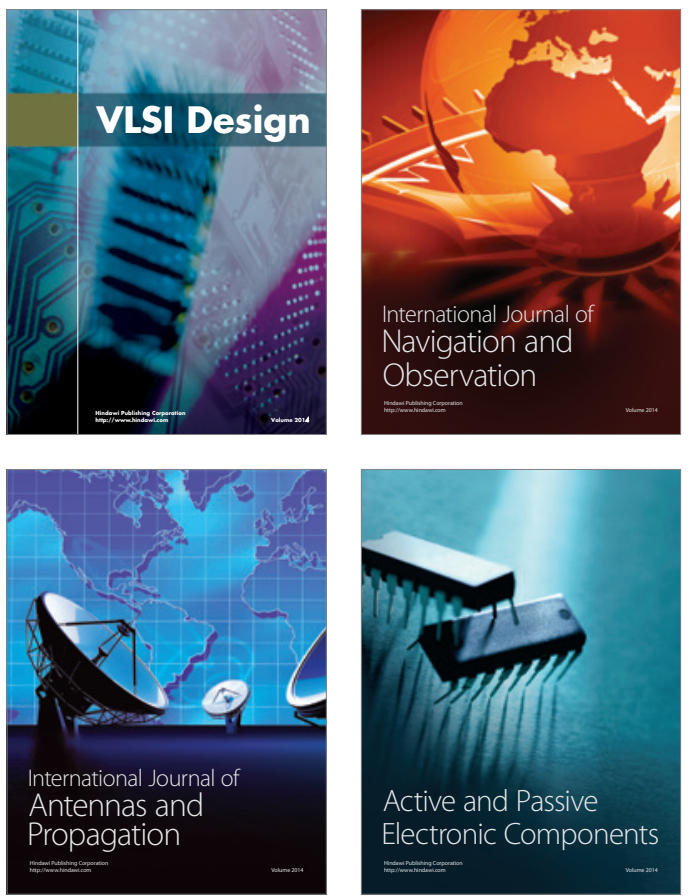
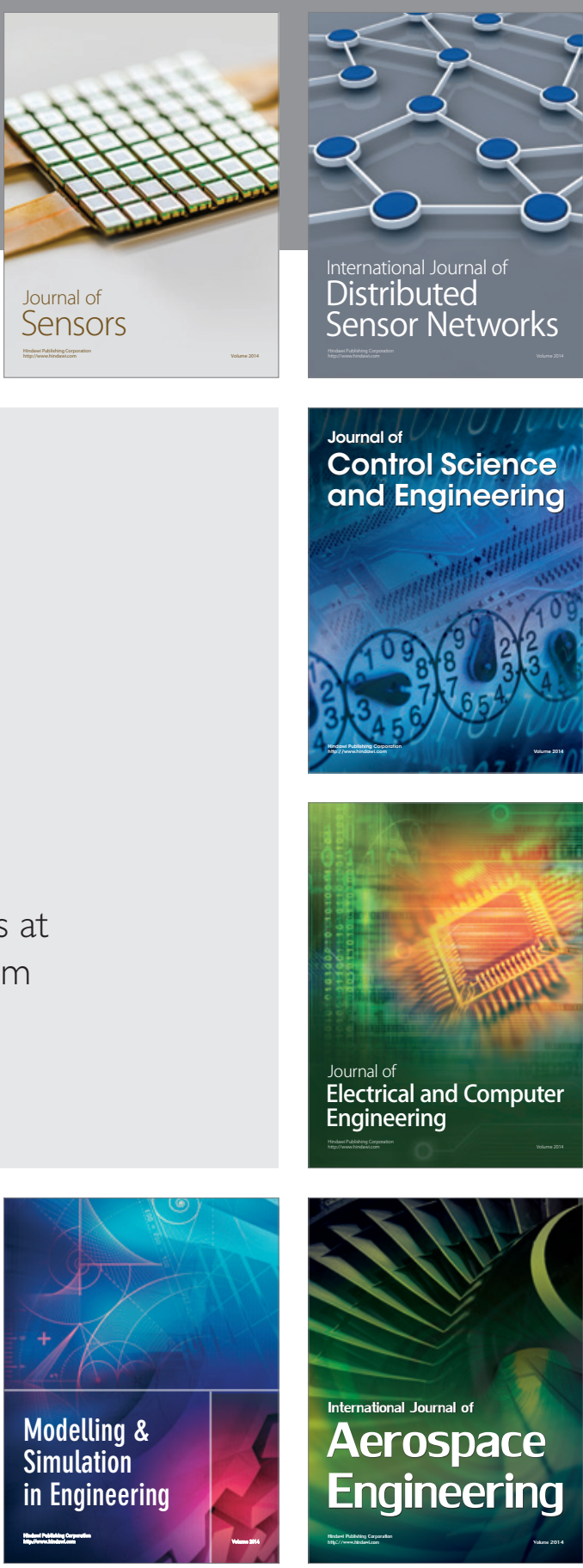

International Journal of

Distributed

Sensor Networks

$-$

Joumal of

Control Science

and Engineering
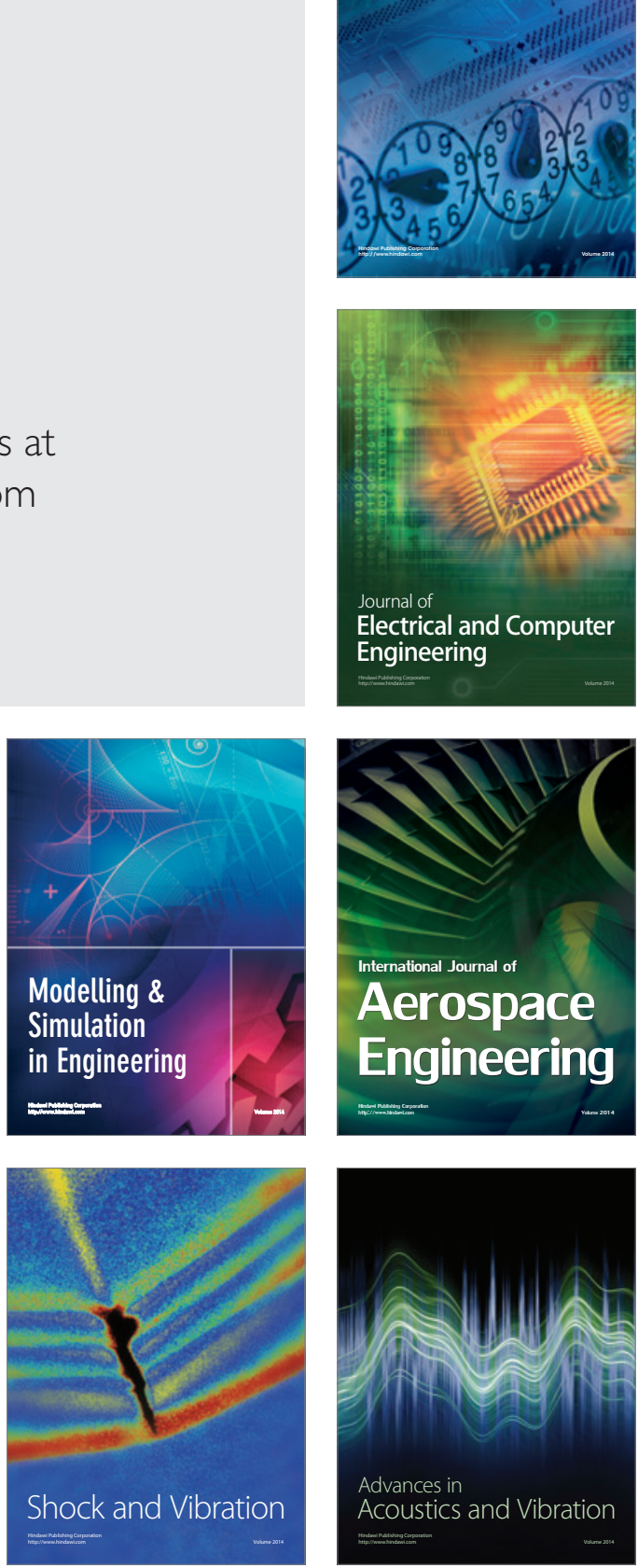